\title{
Surface features of Zr-based and Ti-based metallic glasses by ion irradiation
}

\author{
Z. Hu ${ }^{\text {a }}$, Z.Q. Zhao ${ }^{\text {b,* }}$, Y.D. Wu ${ }^{\text {b }}$, T. Lu $^{\text {a }}$, J.S. Xing ${ }^{\text {a }}$, B.C. Wei ${ }^{\text {a,* }}$ \\ ${ }^{a}$ Key Laboratory of Microgravity (National Microgravity Laboratory), Institute of Mechanics, Chinese Academy of Sciences, Beijing 100190, China \\ ${ }^{\mathrm{b}}$ School of Physics, Peking University, State Key Laboratory of Nuclear Physics and Technology, Institute of Heavy Ion Physics, Beijing 100871, China
}

\section{A R T I C L E I N F O}

\section{Article history:}

Received 23 September 2011

Received in revised form

23 February 2012

Accepted 5 March 2012

\section{Keywords:}

Metallic glasses

Ion irradiation

Surface features

Irradiation damage

\begin{abstract}
A B S T R A C T
Due to a lack of crystalline structures and grain boundaries, metallic glasses exhibit extremely high strength and superior resistance to corrosion. They are also supposed to be resistant against displacive irradiation due to their inherent disordered structure, thereby are potential candidates for applications in irradiation environments. In this work, the irradiation effects of $\mathrm{Zr}$ - and Ti- based bulk metallic glasses (BMGs) under heavy ions irradiation were investigated. The results showed that the Zr-based BMG is more resistant to the $\mathrm{Cl}$ ion irradiation with no structural transition and distinct damage subjected to high irradiation fluence. In contrast, the Ti-based BMG exhibits unique damage morphology with respect to the Zr-based BMG and other reported metallic glasses material. Two kinds of damage pits in micrometer scale form on the irradiated surface, and distinct viscous flow takes place. The formation mechanism of the unique irradiation damage feature is discussed.
\end{abstract}

(c) 2012 Elsevier Ltd. All rights reserved.

\section{Introduction}

Metallic glasses have been a subject of great interest during the past decades because of their unique mechanical and chemical properties like high strength, superior resistance to corrosion [1-4]. Due to their inherent disordered structure, they are supposed to be resistant against displacive irradiation. For this reason, these materials are potential candidates for applications in irradiation environments, for example fusion, spallation sources, etc. [5-7]. Many researches have shown that swift heavy-ion irradiation can induce some experimentally well-established phenomena in metallic glasses, like anisotropic growth and the change in electrical resistivity [8-10]. The understanding of the operative mechanism, however, is still quite incomplete [9,11]. Under heavy ion irradiation activated entities in metallic glasses are expected to rearrange pretty freely during resolidification. On the other hand, they may also develop ordered structure due to the enhanced atomic mobility [12-14]. A variety of multi-component bulk metallic glasses (BMGs) with higher glass forming ability and tunable composition/properties have recently been developed. However, the studies on the irradiation effect in BMGs are still limited [15-17], especially on the irradiation damage feature. In this work, structural stability and surface damage of Zr-based and

\footnotetext{
* Corresponding authors. Tel.: +86 10 82544118; fax: +86 1082544096.

E-mail addresses: zqzhao@pku.edu.cn (Z.Q. Zhao), weibc@imech.ac.cn (B.C. Wei).
}

Ti-based BMGs under $\mathrm{Cl}^{4+}$ ion irradiation with projectile energy of $20 \mathrm{MeV}$ have been investigated. The two BMG systems exhibited quite different irradiation response, especially their damage morphology. These results may provide some useful information on the understanding of the ion irradiation effect in metallic glasses.

\section{Experimental}

$\mathrm{Ti}_{40} \mathrm{Zr}_{25} \mathrm{Be}_{30} \mathrm{Cr}_{5}$ and $\mathrm{Zr}_{47.9} \mathrm{Ti}_{0.3} \mathrm{Ni}_{3.1} \mathrm{Cu}_{39.3} \mathrm{Al}_{9.4} \mathrm{BMGs}$ in the shape of cylindrical rods with $5 \mathrm{~mm}$ diameter were prepared by arcmelting a mixture of elements with purity higher than $99.9 \%$ in an argon atmosphere and then chill-casting into a copper mold. Specimens $3 \mathrm{~mm}$ in length were cut from these rods. Surfaces of samples were mechanically polished to a mirror finish and cleaned ultrasonically prior to the irradiation experiments. The samples were irradiated with $\mathrm{Cl}^{4+}$ ion beam of $20 \mathrm{MeV}$ energy using a $2 \times 6 \mathrm{MV}$ tandem accelerator with fluences from $4.8 \times 10^{14}$ to $1.61 \times 10^{16}$ ions $/ \mathrm{cm}^{2}$. The parameters of the ion beams and the displacement damage were calculated using SRIM2008 code [18]. During ion irradiation, the beam size was $\sim 2.5 \times 1.8 \mathrm{~cm}^{2}$ and the sample holder was cooled by a liquid nitrogen cooling system. The target surface was perpendicular to ion beam direction.

The structure of the unirradiated and irradiated samples was studied by $\mathrm{X}$-ray diffraction (XRD) using $\mathrm{Cu} \mathrm{K} \alpha$ radiation. The thermal analysis was conducted using a differential scanning calorimeter (Netzsch DSC 404C) at a heating rate of $20{ }^{\circ} \mathrm{C} / \mathrm{min}$ under argon atmosphere. The morphology of irradiated samples 
was studied by scanning electron microscope (SEM) and atomic force microscope (AFM).

\section{Results and discussion}

The DSC curves of the two as-cast BMGs are shown in Fig. 1. Distinct glass transition process followed by sharp crystallization events, which are typical feature of amorphous alloy can clearly be observed in the curves of the samples. The glass transition temperature $\left(T_{\mathrm{g}}\right)$, onset temperature of crystallization $\left(T_{\mathrm{x}}\right)$, and supercooled liquid region $\left(\Delta T_{\mathrm{x}}=T_{\mathrm{x}}-T_{\mathrm{g}}\right)$ of the Ti-based BMG sample are 325,418 and $93{ }^{\circ} \mathrm{C}$, respectively. While the corresponding characteristics parameters for the $\mathrm{Zr}$-based BMG sample are 427,490 and $63{ }^{\circ} \mathrm{C}$, respectively. The mean projected ranges $\left(R_{\mathrm{p}}\right)$ for $20 \mathrm{MeV} \mathrm{Cl}^{4+}$ ions in the $\mathrm{Zr}$-based and Ti-based BMGs are about $4.3 \mu \mathrm{m}$ and $5.1 \mu \mathrm{m}$, respectively by calculating with SRIM2008 code. The details about sample irradiation and the corresponding displacement damage (dpa- displacement per atom) are given in Table 1.

XRD patterns obtained from the samples before and after ion irradiation experiments are shown in Fig. 2. The as-cast $\mathrm{Zr}$ - and Tibased BMGs both exhibit only one broad diffraction peak without any sharp Bragg peaks, further confirming the amorphous structure. The irradiated Ti-based BMGs keep its amorphous structure up to the displacement damage of $8 \mathrm{dpa}$. A small amount of fcc-Ti crystals can be found after irradiation at 12 dpa (Fig. 2a). In contrast, the $\mathrm{Zr}$-based BMG retains its amorphous structure within the studied displacement damage range, even at $17 \mathrm{dpa}$. This demonstrates that the Zr-based BMG is more structurally stable with respect to the Ti-based BMG under similar radiation condition. We can estimate the samples temperature is much lower than the $T_{\mathrm{g}}$ of Ti-based BMG $\left(325^{\circ} \mathrm{C}\right)$ from XRD patterns, or else the Ti-based samples will be obviously crystallized after irradiation for $5.1 \mathrm{~h}$.

Typical SEM images of unirradiated and irradiated Ti-based BMG samples with fluences from $4.8 \times 10^{14}$ to $1.61 \times 10^{16}$ ions/ $\mathrm{cm}^{2}$ are shown in Fig. 3. For fluences $<4.8 \times 10^{14}$ ions $/ \mathrm{cm}^{2}$, the surface of the irradiated is essentially featureless (Fig. $3 \mathrm{~b}$ ), and nearly identical to unirradiated sample (Fig. 3a). After exposure to ion fluence of $1.14 \times 10^{16}$ ions $/ \mathrm{cm}^{2}$, it is interesting to find that some surface features were observed on the very smooth Ti-based specimen surface (Fig. 3c). There are mainly two kinds of damage pits on the irradiated surface. One is craters-like with an average

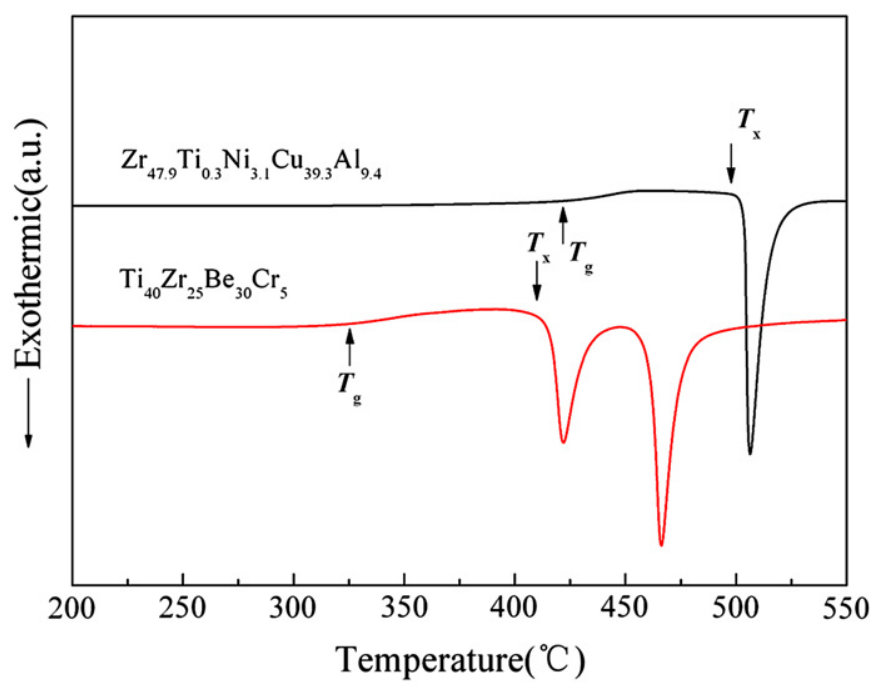

Fig. 1. DSC curves of as-cast Ti-based and Zr-based BMGs at the heating rate of $20^{\circ} \mathrm{C} / \mathrm{min}$
Table 1

Irradiation parameters and displacement damage.

\begin{tabular}{llllc}
\hline $\begin{array}{l}\text { Energy/Ion } \\
\text { beam }\end{array}$ & $\begin{array}{l}\text { Total fluence } \\
\left(\text { ions } / \mathrm{cm}^{2}\right)\end{array}$ & $\begin{array}{l}\text { Current density } \\
\left(\mu \mathrm{A} / \mathrm{cm}^{2}\right)\end{array}$ & \multicolumn{2}{c}{ Displacement damage (dpa) } \\
\cline { 4 - 5 } & & Ti-based & Zr-based \\
\hline $20 \mathrm{MeV} \mathrm{Cl}^{4+}$ & $4.8 \times 10^{14}$ & 2 & 0.4 & 0.5 \\
& $1.14 \times 10^{16}$ & 2.25 & 8 & 12 \\
& $1.61 \times 10^{16}$ & 5.5 & 12 & 17 \\
\hline
\end{tabular}

rim-to-rim diameters of about $3 \mu \mathrm{m}$. The other is blister-like, possessing a much larger size ranging from 5 to $20 \mu \mathrm{m}$. The average diameter for the blister-like pits is about $15 \mu \mathrm{m}$. The total number density of the two kinds of pits is about $1.64 \times 10^{6} / \mathrm{cm}^{2}$ after irradiation at fluence of $1.14 \times 10^{16}$ ions/ $/ \mathrm{cm}^{2}$ through analyzing the images of the whole irradiated region. At further higher fluence, the two kinds of damage pits still exist, with their size changed insignificantly. The number density of the two kinds pits increases to about $1.89 \times 10^{6} / \mathrm{cm}^{2}$ at the irradiation fluence of $1.61 \times 10^{16}$ ions $/ \mathrm{cm}^{2}$. Meanwhile, the depth of the craters-like pits increases also with fluence (Fig. 3d). For further demonstrate the damage morphology, AFM was used to characterize the surface features of the irradiated Ti-based BMG. Typical AFM images and the corresponding cross-section profiles of the two types of damage pits under irradiation fluence of $1.14 \times 10^{16}$ ions $/ \mathrm{cm}^{2}$ are shown in Fig. 4. The craters-like pits are relative irregular cone shape, and have a sharp bottom with a typical depth of about $200 \mathrm{~nm}$ (Fig. 4a,c). While the blister-like pits are in a nearly perfect round shape, and have a flat bottom with $100 \sim 200 \mathrm{~nm}$ depth (Fig. 4b,d). It should be noted that distinct smoothing takes place on the surface of the pit's bottom, and ditch-dike structure forms near the edge of the blister-like pits. The height of the ditch is about $120 \mathrm{~nm}$, while the dike has a gentle slope with the depth of about $50 \mathrm{~nm}$.

The surface response of $\mathrm{Zr}$-based BMG to irradiation was also studied. Typical morphologies of the samples irradiated at $4.8 \times 10^{14}$ and $1.61 \times 10^{16}$ ions $/ \mathrm{cm}^{2}$ are shown in Fig. 5a and b, respectively. No distinct irradiation damage features can be found on the surface up to an irradiation fluence of $1.61 \times 10^{16}$ ions $/ \mathrm{cm}^{2}$, which corresponds to a high displacement damage of $17 \mathrm{dpa}$.

From the surface features of the irradiated Ti-based BMG, it can be found that the size of craters-like damage pits is in the scale of a few micrometers, unlike the nano-scaled craters produced by energetic ion and cluster ion impact in other metallic materials [19-21]. Although some models may provide a reasonable explanation for the formation of craters, like thermal spike model, they are confined to nano-scale. Thereby, the formation of micro-scaled craters in the present work cannot be explained by this classic model. During the slowing down process of energetic atoms in a solid, the kinetic energy of a moving ion is partially transferred to host atoms by elastic collisions. The recoiling atoms, in turn, transfer part of their energy to other atoms. Hence a cascade evolves resulting in the formation of a highly disrupted, very hot, region inside the solid. The results of MD simulations by Averback and Ghaly [22] indeed indicate that large pressures may occur in the region, even up to $5 \sim 8 \mathrm{GPa}$ existing at the core of a very small spike within a few ps following ion impact. Micro-explosion occurs when the liquid zone is so close to a surface that the pressure wave from the cascade essentially ruptures the surface. The projected ranges of ion are similar for the two BMGs studied here $(\sim 5 \mu \mathrm{m}$ as calculated by SRIM2008 code). The different response to the irradiation should be related to their difference in material nature. The two BMGs possess similar compressive strength close to $2 \mathrm{GPa}$. The major difference between the two alloys lies in their glass transition temperature and the span of the supercooled liquid region. $T_{\mathrm{g}}$ of the Ti-based BMG is about $100{ }^{\circ} \mathrm{C}$ lower than that of the $\mathrm{Zr}$-based $\mathrm{BMG}$, and $\Delta T_{\mathrm{X}}$ of the former alloy is $30{ }^{\circ} \mathrm{C}$ wider. Though direct 

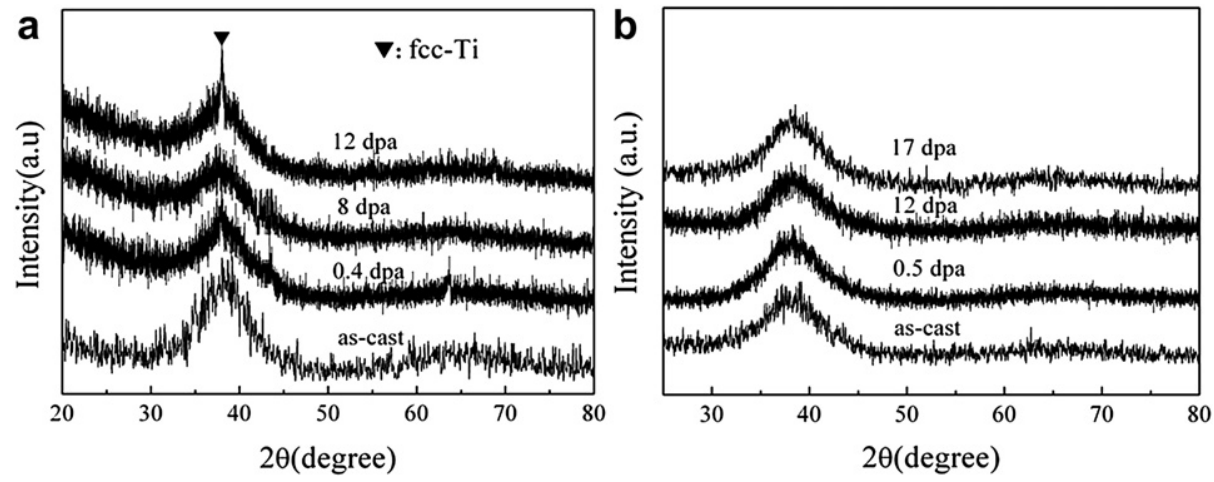

Fig. 2. XRD patterns of (a) Ti-based and (b) Zr-based BMGs before and after ion irradiation.

temperature measurement was not conducted due to the instrumental limitation, the temperature of the sample is supposed to be much lower than the $T_{\mathrm{g}}$ of Ti-based BMG $\left(325^{\circ} \mathrm{C}\right)$, otherwise significant crystallization will take place upon annealing for a long duration (about $5.1 \mathrm{~h}$ for the displacement damage of $8 \mathrm{dpa}$ for the Ti-based BMG). However, the Ti-based BMG will still exhibit lower viscosity than the $\mathrm{Zr}$-based BMG at the same temperature due to the lower $T_{\mathrm{g}}$, enabling an easier viscous flow under irradiation induced stress. Furthermore, the lower $T_{\mathrm{g}}$ encourage the formation of relative large liquid volume around the ion tracks, and the large $\Delta T_{\mathrm{x}}$ provides a wide time window for viscous flow and relaxation. In addition, due to the dense displacement cascades located near surface for high current density, hot and low viscous fluids tend to form a larger liquid phase, which is frozen during subsequent cooling. As can be seen in Fig. 4a and c, larger craters (a few micrometers) coexist with some very small ones $(<1 \mu \mathrm{m})$. The lower binding energy of the liquid phase gives rise to a low flow stress. Therefore, a micro-explosion and viscous flow coupling mechanism may offer an explanation for the formation of microscale craters in the Ti-based BMG. An alternative explanation for the occurrence of craters could be irradiation sputtering. The sputter yield of Ti-based and Zr-based is 0.103 and 0.096 Atoms/ion, respectively, which is calculated using SRIM2008 code. There are no obvious differences in sputter yield between the two alloy systems. Additionally, the observed dips have a depth $>200 \mathrm{~nm}$, which is much larger than the calculated sputter yield for the present materials. These results indicate that the contribution of ion sputtering on the forming of different damage morphology in the two alloy systems can be neglected.

The blister-like damage pits were also found on the surface of the irradiated Ti-based BMG. They exhibit a large diameter up to $20 \mu \mathrm{m}$ and a very smooth bottom. The quite different shape of these blister-like pits with the previous craters-like ones excludes the possibility that they are the product of accumulating the small craters-like pits. The observed blister-like damage is also rather different from blisters induced by gas atom implantation in metallic glasses [23,24], as no sign of blistering and flaking can be found throughout the sample. Moreover, we observed the similar blisterlike pits on the surface samples irradiated by $\mathrm{Si}^{3+}$ ion, which is not a gas element. It is worth noting that distinct ditch-dike structures
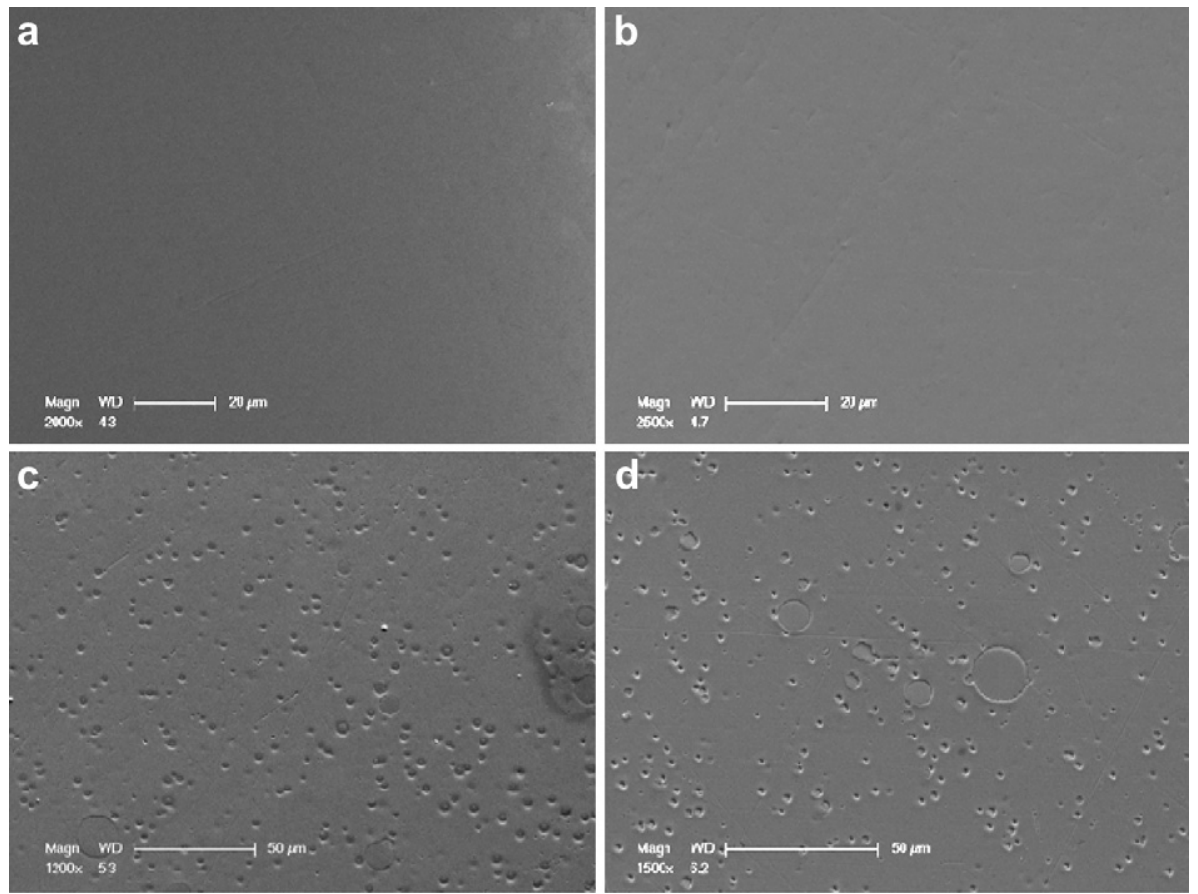

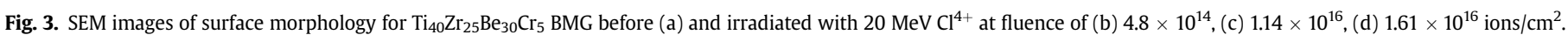


a
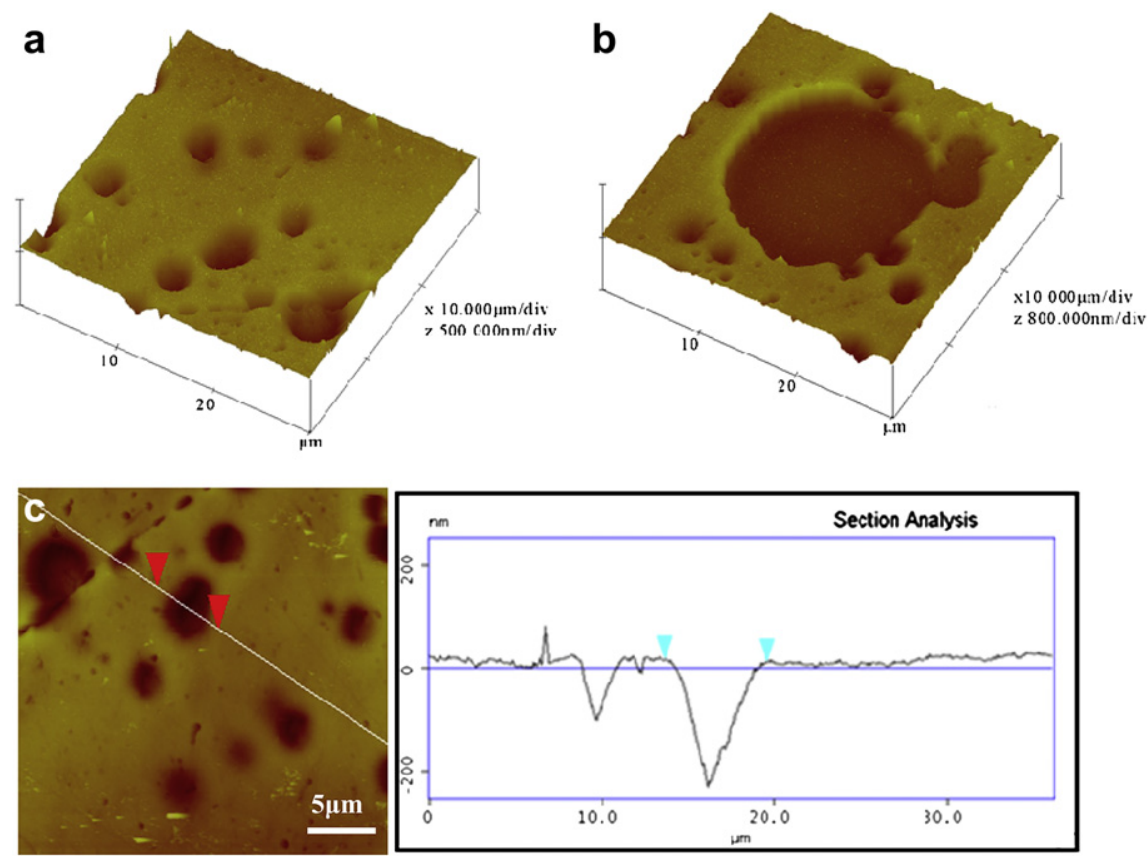

d
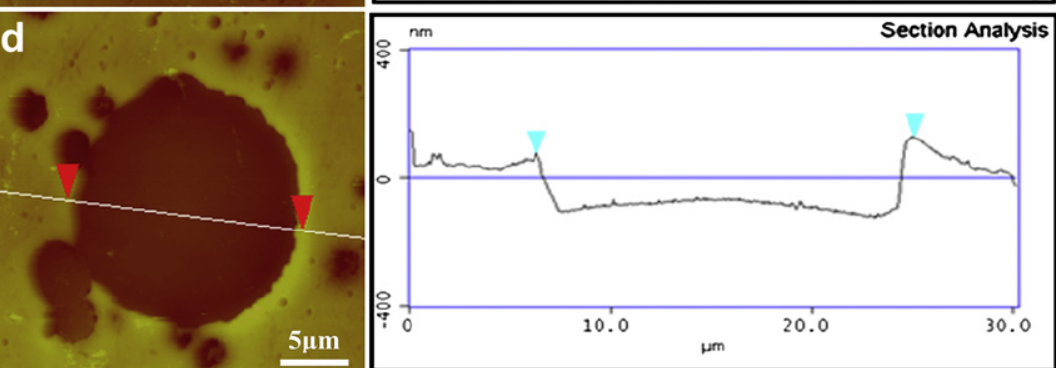

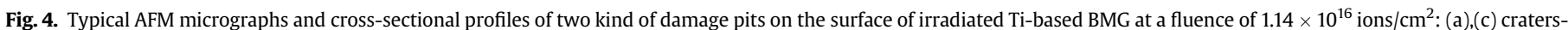
like and (b),(d) blister-like.
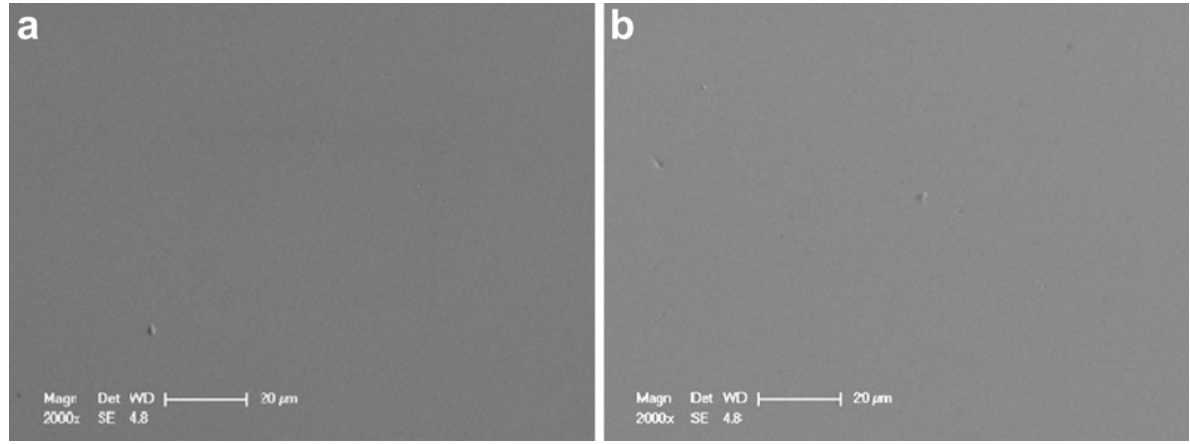

Fig. 5. SEM images of surface morphology for $\mathrm{Zr}_{47.9} \mathrm{Ti}_{0.3} \mathrm{Ni}_{3.1} \mathrm{Cu}_{39.3} \mathrm{Al}_{9.4} \mathrm{BMG}$ irradiated with $20 \mathrm{MeV} \mathrm{Cl}{ }^{4+}$ at fluence of $(\mathrm{a}) 4.8 \times 10^{14}$, (b) $1.61 \times 10^{16}$ ions/cm ${ }^{2}$.

form around the edge of the pits (Fig. 4). This further confirms that significant viscous flow and mass transfer take place on the surface subjected to irradiation. The well round shape of the large blisterlike pits may also suggests that their formation is closely related to the formation of a thin liquid film on the surface. While, the absence of micro-scale damage pits and viscous flow phenomenon in the $\mathrm{Zr}$-based BMG is due to its relatively high $T_{\mathrm{g}}$ and narrow supercooled liquid region. The unique irradiation damage morphology with respect to other metallic glasses under ion irradiation is related to its quite low $T_{\mathrm{g}}$ and a wide supercooled liquid region. Further studies are needed to clarify the mechanism responsible for viscous flow in this kind of low $T_{\mathrm{g}}$ metallic glass materials.

\section{Conclusions}

Structural and morphological responses of $\mathrm{Ti}$ - and $\mathrm{Zr}$ - based $\mathrm{BMGs}$ to high energy $\mathrm{Cl}$ ion irradiation were studied in this work. Crystallization takes place in Ti-based BMG at displacement damage higher than $12 \mathrm{dpa}$, while the $\mathrm{Zr}$-based BMG remain its amorphous structure up to $17 \mathrm{dpa}$, indicating a better irradiation resistance for the latter BMG. The two BMGs exhibit quite different 
damage morphology. Craters-like pits in a few micrometers scale and blister-like pits with size up to $20 \mu \mathrm{m}$ are found on the irradiated surface irradiated by fluence higher than $1.14 \times 10^{16}$ ions/ $\mathrm{cm}^{2}$. Viscous flow can also be found on the surface. However, the Zr-based BMG does not exhibit any micro-scaled damage pits and viscous flow. The unique damage morphology in the Ti-based BMG is related to its low glass transition temperature and wide supercooled liquid region, which give rise to a micro-explosion and viscous flow process.

\section{Acknowledgments}

This work is financially supported by the National Nature Science Foundation of China (Grant Nos. 51071166 and 10675010) and National Basic Research Program of China (973 Program, No. 2010CB832902 and 2010CB832904).

\section{References}

[1] Greer A, Ma E. Bulk metallic glasses: at the cutting edge of metals research. Mrs Bull 2007;32:611-9.

[2] Johnson WL, Demetriou MD, Harmon JS, Lind ML, Samwer K. Rheology and ultrasonic properties of metallic glass-forming liquids: a potential energy landscape perspective. Mrs Bull 2007;32:644-50.

[3] Ashby M, Greer A. Metallic glasses as structural materials. Scripta Mater 2006; 54:321-6.

[4] Schroers J. Processing of bulk metallic glass. Adv Mater 2010;22:1566-97.

[5] Bardamid AF, Voitsenya VS, Lytvyn OS, Lytvyn PM, Konovalov VG, Shapoval AN, et al. Observation of unique blister-like surface features on amorphous metallic alloys following bombardment with deuterium ions. J Nucl Mater 2008;376:125-7.

[6] Trinkaus H. Local stress-relaxation in thermal spikes as a possible cause for creep and macroscopic stress-relaxation of amorphous solids under irradiation. J Nucl Mater 1995;223:196-201.

[7] Mayr SG. Impact of ion irradiation on the thermal, structural, and mechanical properties of metallic glasses. Phys Rev B 2005;71:144109.
[8] Klaumunzer S, Schumacher G. Dramatic growth of glassy Pd80Si20 during heavy-ion irradiation. Phys Rev Lett 1983:51:1987-90.

[9] Hou MD, Klaumunzer S, Schumacher G. Dimensional changes of metallic glasses during bombardment with fast heavy-ions. Phys Rev B 1990;41: 1144-57.

[10] Petrusenko Y, Bakai A, Neklyudov I, Borysenko V, Barankov D, Astakhov O, et al. Recovery kinetics and ordering in irradiated bulk metallic glasses. Probl Atom Sci Technol Ser Phys Radiat Effect Radiat Mater Sci; 2008:62-5.

[11] Trinkaus H, Ryazanov AI. Viscoelastic model for the plastic-flow of amorphous solids under energetic ion-bombardment. Phys Rev Lett 1995;74: 5072-5.

[12] Nagata S, Sasase M, Takahiro K, Tsuchiya B, Inouye A, Yamamoto S, et al. Ion induced structural modification and nano-crystalline formation of $\mathrm{Zr}-\mathrm{Al}-\mathrm{Ni}-\mathrm{Cu}$ metallic glasses. Nucl Instrum Meth B 2009;267:1514-7.

[13] Carter J, Fu EG, Martin M, Xie G, Zhang X, Wang YQ et al. Effects of Cu ion irradiation in Cu50Zr45Ti5 metallic glass. Scripta Mater 2009:61:265-8.

[14] Nagata S, Higashi S, Tsuchiya B, Toh K, Shikama T, Takahiro K, et al. Ion irradiation effects on amorphization and thermal crystallization in $\mathrm{Zr}-\mathrm{Al}-\mathrm{Ni}-\mathrm{Cu}$ alloys. Nucl Instrum Meth B 2007;257:420-3.

[15] Carter J, Fu EG, Bassiri G, Dvorak BM, David Theodore N, Xie G, et al. Effects of ion irradiation in metallic glasses. Nucl Instrum Meth B 2009;267:1518-21.

[16] Raghavan R, Boopathy K, Ghisleni R, Pouchon MA, Ramamurty U, Michler J. Ion irradiation enhances the mechanical performance of metallic glasses. Scripta Mater 2010;62:462-5.

[17] Yang YZ, Tao PJ, Li GQ, Mu ZX, Ru Q, Xie ZW, et al. Effects of ion implantation on surface structures and properties for bulk metallic glass. Intermetallics 2009; $17: 722-6$

[18] Birtcher RC, Donnelly SE. Plastic flow induced by single ion impacts on gold. Mater Res Soc Symp Proc 1997;439:355-60.

[19] Donnelly SE, Birtcher RC. Radiation damage from single heavy ion impacts on metal surfaces. Proc SPIE 1998;3413:174-82.

[20] Birtcher RC, Donnelly SE, Schlutig S. Nanoparticle ejection from Au induced by single Xe ion impacts. Phys Rev Lett 2000;85:4968-71.

[21] Donnelly SE, Birtcher RC. Heavy ion cratering of gold. Phys Rev B 1997;56: 13599-602.

[22] Averback RS, Ghaly M. A model for surface damage in ion-irradiated solids J Appl Phys 1994;76:3908-10.

[23] Tyagi AK, Nandedkar RV, Krishan K. Blistering, flaking and bubble formation in metal metalloid metallic glasses bombarded with helium-ions. J Nucl Mater 1983;116:29-39.

[24] Hou MD, Liu J, Zhang QX, Wang ZG, Sun YM, Zhu ZY, et al. Investigation on the surface topography of amorphous alloys implanted with helium ions. Mater Adv Energy Syst Fission Fusion Eng, Proceedings; 2003:377-84. 